\title{
"Cut-bristles": a sex-limited mutant phenotype of male orbital bristles of Ceratitis capitata
}

\author{
C Lemaître, JP Carante \\ Université C Bernard, Lyon 1 et Institut Universitaire de Technologie A, \\ URA 243 Biométrie, Génétique et Biologie des Populations, \\ 43 Bd du 11 Novembre 1918, 69622 Villeurbanne, France
}

(Received 15 July 1991; accepted 15 May 1992)

\begin{abstract}
Summary - The "cut-bristles" phenotype, a new mutant of Ceratitis capitata, is characterised by the disappearance of the lancet-shape bristles, a male sex-limited trait. This mutation seems to be under the control of 2 major recessive genes, probably with several additional minor ones, which account for incomplete and variable penetrance. Two models are compatible with our data: 2 autosomal syntenic, but distant genes (no recombination in males) or 1 sex-linked and another autosomal gene.
\end{abstract}

Mediterranean fruit fly / Ceratitis capitata / "cut-bristles" mutant

Résumé - Étude génétique d'une mutation morphologique de Ceratitis capitata: «cutbristles». Le phénotype «cut-bristles» correspond à la disparition des soies orbitales en forme de lance, attributs caractéristiques du sexe mâle. Ce phénotype se révèle être sous le contrôle de 2 gènes majeurs récessifs et sans doute de plusieurs autres gènes mineurs, permettant d'expliquer la pénétrance variable et incomplète observée pour ce caractère. Deux modèles sont compatibles avec nos résultats: 2 gènes autosorniques, synténiques mais éloignés l'un de l'autre (pas de recombinaison chez le mâle) ou un gène lié au sexe et un autre autosomique.

mouche méditerranéenne des fruits / Ceratitis capitata / mutant «cut-bristles» 


\section{INTRODUCTION}

Over the past decade, genetic knowledge of the medfly increased rapidly as the need for pest control programs was recognized (see Saul, 1986, for review). There are, however, still only few genetically marked strains available for ecological studies, and the list established by Rössler (1989) constitutes a poor set compared with other pests. It is thus necessary to consider any kind of morphological mutants, even if their mode of inheritance is still unclear.

Four orbital bristle mutants are mentioned in the literature, but only 2 of them have been analyzed. The first mutation, found by Cavicchi (1973), involved chaetae shape and stem colour and was recessive, monogenic and autosomal. The second mutant, "double-chaetae", isolated by Rössler and Koltin (1976) concerned the number of bristles; its underlying genetic system was not clear and did not conform well to the segregation ratios expected from a single gene model. From further studies, this deviation was attributed to incomplete penetrance and variable expressivity of the character (Rössler, 1982a; Saul and Rössler, 1984). Here we present an additional morphological mutation we named "cut-bristles". This variant concerns the characteristic lancet shape bristles of Ceratitis capitata males, an ornament described as "subarticulate horns, planted between the eyes..." by Mac Leay (1829).

\section{MATERIALS AND METHODS}

We used 2 strains: a wild strain, donated by a French laboratory in 1968 (Avignon) and a mutant strain, isolated from another strain (inbred because of a selection carried out on a nutritional criterion 1 year ago) itself originated from a strain (Antibes) kept in the laboratory since 1978. Both had been caught in Tunisia, but at different geographical sites and times. These strains were reared under laboratory conditions for several years (see Carante and Lemaitre, 1990 for rearing conditions).

Virgin females were isolated in separate containers within $24 \mathrm{~h}$ of emergence, and were mated within the following $5 \mathrm{~d}$. For transfer and scoring adults were immobilized by chilling at $10^{\circ} \mathrm{C}$.

In each cross, the flies were mated (at least 5 pairs of flies) or in single pairs (single pairs were always less fecund than mass-mated flies and were often sterile). Two repetitions were carried out, and their results, found not to be statistically different by $\chi^{2}$ test, were pooled.

\section{RESULTS AND DISCUSSION}

\section{Description of the phenotype}

The "cut-bristles" trait corresponds to the absence of anterior frontal orbital bristles, exactly as if they were cut at their base shaft. Some males bear only one orbital bristle, and they are referred to as "uni-bristle" type (see fig 1). We used this name to distinguish our mutation from previous "chaetaeless" traits (Anonymous, 

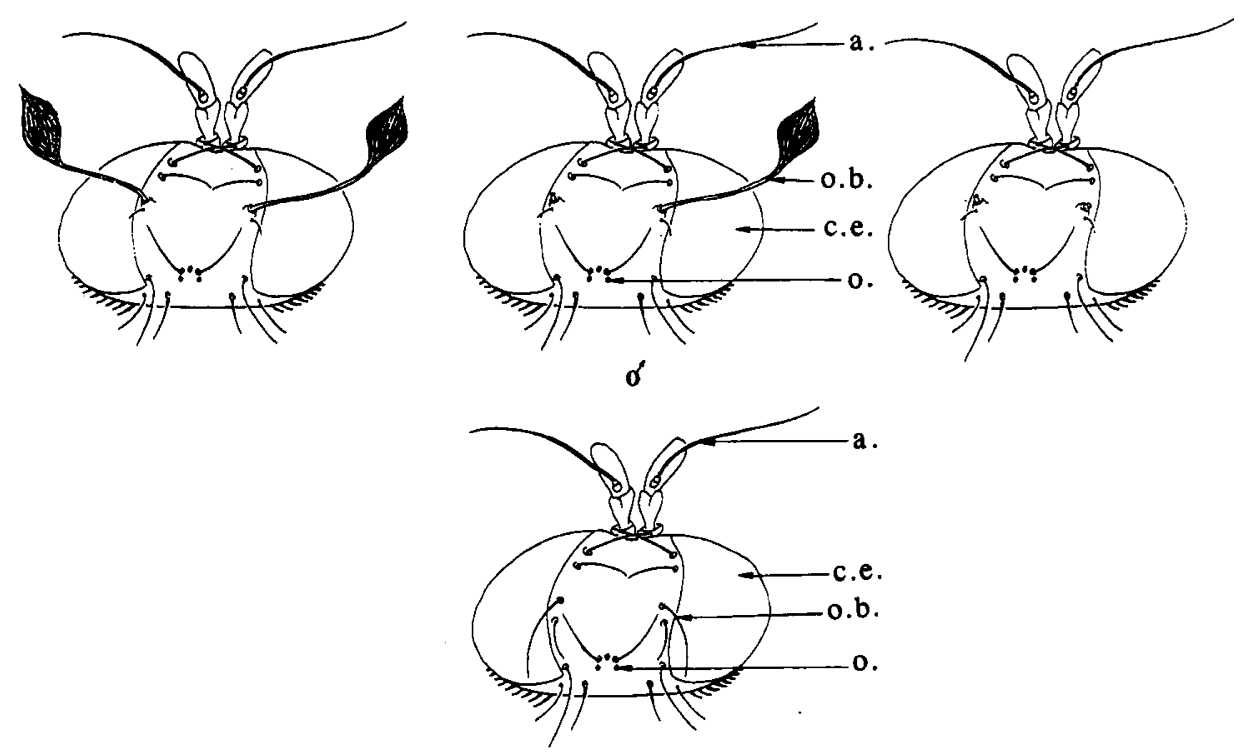

q

Fig 1. Diagrams of the heads of the wild and "cut-bristles" phenotypes. Upper diagram corresponds to males. From left to right: wild type, uni-bristle type, "cut-bristles" type. Lower diagram corresponds to females: all of them have 2 classic shape orbital bristles, instead of the enlarged type carried by wild type males. $a=$ antenna; $c e=$ compound eye $\mathrm{o}=$ ocellus $; \mathrm{ob}=$ orbital bristle.

1980 and Lifschitz, 1985) which are simply mentioned as autosomal incomplete dominant traits, without any analysis.

The "cut-bristles" trait, or even a simple shape change of the analogous bristles, has never been observed in females; the genetic analysis was thus based only on the male progeny phenotypes.

Dissection of pharate adult puparia 1 day before emergence showed that the orbital bristles of "cut-bristles" males were normally formed but unpigmented, contrary to those of wild males. When a "cut-bristles" male was removed from its nymphal wrapping, the bristle shaft broke most of the time; this never happened with wild males. The mutant phenotype, therefore, came from the break of the orbital bristle shaft at emergence time because of its brittleness.

\section{Selection and establisment of a "cut-bristles" strain}

The first "cut-bristles" male was found in 1980, in an inbred line. This male was mated to its sisters, "cut-bristles" males were sib-crossed each generation, and a "cut-bristles" strain was established from that time. The fraction of "cut-bristles" males reached its maximum (ie $92 \%$ ) within 6 generations, but the selection pressure was maintained until the 17 th generation before being stopped. This relaxation of selection did not cause a decrease of mutant-type frequency in the 4 subsequent 
generations, so we considered our selected strain as a truc-brecding one. Despite the fact that mutant females were indistinguishable from wild-type, we assumed that females of the selected strain were of mutant genotype, and they will be referred to as "mutant females" in the text.

The persistence of a few wild-type (about 2\%) and uni-bristle type (about 6\%) males throughout the generations of selection is troublesome. It demonstrates some variability in the expression and penetrance of the phenotype.

No "uni-bristle" male has ever been found in the wild strain.

\section{Inheritance of the "cut-bristles" trait}

Male and female mutants were crossed to the wild-type laboratory strain (Avignon). These crosses yielded wild-type progeny, with a very small proportion of males with 1 or 0 bristle (table I). The mutation is thus recessive. The appearance of a few mutants may result either from the presence of individuals heterozygous for the mutation in the wild strain, from non-virgin mutant females, or the occurrence of phenocopies resulting from particular environmental conditions. To check some of these points the uni-bristle $F_{1}$ males were pair-mated to virgin "mutant females". These crosses produced 85 wild-typc, 38 uni-bristle and 144 cut-bristles males. This phenotypic distribution was similar to that produced by the $\mathrm{F}_{1}$ wildtype males crossed with "mutant females" ( $\mathrm{F}_{2 \mathrm{am}}$ and $\mathrm{F}_{2 \mathrm{bm}}$ in table $\mathrm{I} ; \chi^{2}=6.13$, for $4 d f, P>0.05)$. From these results we infer that $F_{1}$ uni-bristle males had the same

Table I. Progeny numbers from various crosses involving wild-type and "cut-bristles flies.

$\begin{array}{lccccc}\hline \text { Mating type } & \begin{array}{c}\text { Progeny } \\ \text { type }\end{array} & \multicolumn{2}{c}{\text { No of male progeny }} & \begin{array}{c}\text { Ratio of } \\ \text { cut-bristles" } \\ \text { males }\end{array} & \chi^{2} \\$\cline { 3 - 4 } \text {$\left.Male } \times \text { female } & & \text { Cut bristles } & \begin{array}{c}\text { Uni-bristle } \\ + \text { wild-type }\end{array} & \\ \hline[\mathrm{m}] \times[+] & \mathrm{F}_{1 \mathrm{a}} & 2 & 8+368 & 0.005 & \\ {[+] \times[\mathrm{m}]} & \mathrm{F}_{1 \mathrm{~b}} & 1 & 20+298 & 0.003\end{array}\right\} 0.188(\mathrm{NS})$

$[\mathrm{m}]$ and $[+]$ symbolize "cut-bristles" and wild types, respectively. $F_{1 a}, F_{1 b}, F_{2 a a}, F_{2 b b}$, $\mathrm{F}_{2 \mathrm{am}}, \mathrm{F}_{2 \mathrm{bm}}, \mathrm{F}_{2 \mathrm{ma}}$ and $\mathrm{F}_{2 \mathrm{mb}}$ correspond to the different progenies. $\mathrm{NS}=$ not significant at the 0.05 level. 
genotype as $\mathrm{F}_{1}$ wild type males. Consequently we postulate that they were hetcrozygous for the studied genetic system; the frequencies of these 2 phenotypes were therefore pooled in statistical analyses. The fact that the same genotype can lead to different phenotypes means that the wild type allele involved was incompletely dominant.

The phenotypic distribution of the progenies of $F_{1}$ sib-crosses $\left(F_{2 a a}\right.$ and $F_{2 b b}$ and $F_{1}$ reciprocal test-crosses $\left(F_{2 a m}\right.$ and $F_{2 b m}$ and $F_{2 m a}$ and $\left.F_{2 m b}\right)$ are not consistent with a single locus model. Morcover, the test-crosses yielded segregation ratios which differed according to the sex of the heterozygous parent. We consider that the genetic system was thus either sex-linked, or at least partly sex influenced. Reciprocal homologous crosses yielded statistically similar progeny distributions (see $\chi^{2}$ in table I), and the ratio values of "cut-bristles" males to males with 1 and 2 bristles suggest a 2-loci model for the genetic control of the mutation.

According to Carante's proposals (1983) these 2 loci can be symbolized by obn2 and obn 3 (from orbital number) and the respective mutant and wild type alleles by obn2(ct), obn2(+) and obn3(br), obn3(+); for brevity, we will use only ct, br or + (the parenthetical part of the locus symbols), so the following allelic associations $(+,+),(\mathrm{ct},+)$ and $(+, \mathrm{br})$ correspond to the wild phenotype and (ct,br) to the mutant one.

Two models are compatible with the results:

\section{Model 1: 2 autosomal loci}

According to the $\mathrm{F}_{1 \mathrm{a}}$ and $\mathrm{F}_{1 \mathrm{~b}}$ progenies, the 2 loci are closely linked, but according to the $\mathrm{F}_{2 \mathrm{ma}}$ and $\mathrm{F}_{2 \mathrm{mb}}$ progenies the 2 loci are independent. To resolve this discrepancy we postulate that: 1 ) the 2 loci belong to the same syntenic group; 2) they are far enough from each other to yield a recombination level in females so high as to seem independent; 3) the recombination level is very low in males as in some other Dipteran species.

According to this hypothesis, all the $\mathrm{F}_{1}$ genotypes are similar, whatever the direction of the cross. The mean frequency value of $\mathrm{F}_{2 \mathrm{ma}}$ and $\mathrm{F}_{2 \mathrm{mb}}$ "cut-bristles" males is 0.26 . These males occur from 1 of the 2 non-recombinant female gamete-types produced by heterozygous $F_{1}$ females. We may thus assume a non-recombination level of 0.52 (and therefore a recombination level of 0.48 ) in females. This high value indicates that the 2 loci are very distant. Accurate location would need further studies using intermediate markers. The mean frequency of $F_{2 a m}$ and $F_{2 b m}$ "cut-bristles" males is 0.46 . These males occur from non-recombinant gametes provided by heterozygous $F_{1}$ males. We estimate the recombination level to be 0.04 in males. Such values conform with previous estimates of Robinson and Van Heemert (1982), Rössler (1982a,b; 1985) and Rössler and Rosenthal (1988). The frequency of $\mathrm{F}_{2 \mathrm{aa}}$ and $\mathrm{F}_{2 \mathrm{bb}}$ "cut-bristles" males, resulting from 2 non-recombinant $\mathrm{F}_{1}$ parental gametes would then be equal to 0.125 . This expected value is not statistically different from the observed results $\left(0.110\right.$ for $\mathrm{F}_{2 \mathrm{aa}}: \chi^{2}=3.594,1 d f, P>0.05$ and 0.134 for $\left.\mathrm{F}_{2 \mathrm{bb}}: \chi^{2}=0.345,1 d f, P>0.05\right)$. 


\section{Model 2: one sex-linked and one autosomal loci}

In medfly the female sex is homogametic and the male is heterogametic (Radu et al, 1975; Saul, 1985; Lifschitz and Cladera, 1989). All the $\mathrm{F}_{1}$ males were thus heterozygous for the autosomal locus, but they differed in the allelic form borne by the X-chromosome: $F_{1 a}$ males presented the wild form and the $F_{1 b}$ males the mutant one. The similar phenotypic distributions of these $2 \mathrm{~F}_{1}$ males (see table I: $\chi^{2}=0188,1 d f, P>0.05$ ), suggest that the 2 alleles involved acted in a similar way and had no additive action upon the trait.

At the $\mathrm{F}_{2}$ generation, the genotypes of the offspring depend only on the mating type, and the expected value of the "cut-bristles" male relative frequency is $1 / 2$ for $F_{2 a m}$ and $F_{2 b m}, 1 / 4$ for $F_{2 m a}$ and $F_{2 m b}, 1 / 8$ for $F_{2 a a}$ and $F_{2 b b}$. The observed results are consistent with these expected values $\left(\chi^{2}=0.467,0.500,0.012,1.026\right.$, 3.594 and 0.345 for $F_{2 a m}, F_{2 b m}, F_{2 m a}, F_{2 m b}, F_{2 a a}$; and $F_{2 b b}$, respectively, with 1 $d f$ and $P>0.05$ ).

Like Rössler and Koltin (1976) with their double chatae mutation, we were confronted in our analyses with the imperfect correspondence between phenotypes and genotypes. $F_{1}$ "uni-bristle" males incontestably behave like $F_{1}$ wild type males when they are crossed with "cut-bristle" females; however, when persistent "unibristle" males of the selected strain are equally crossed with their sisters, they yield a progeny similar to that of "cut-bristles" males. This ambiguity, which would require particular study, could be imputed to modifying minor genes, whose association is removed throughout the selection, interfering with major gene expressivity.

Beside the 2 major genes involved in the genetic determinism of the "cutbristles" phenotype, we must thus consider minor ones, scattered throughout the chromosomes. They may account for incomplete penetrance and variable expressivity of this trait, as well as incomplete dominance of wild-type of $F_{1}$ males.

To set up any population biology or ecology study, markers are essential. At present a maximum of 38 adult morphological mutants of Ceratitis capitata are known, a number which is very likely much smaller because of the high degree of redundancy among them (Rössler, 1989); furthermore, 27 of them are color variants whose stability throughout time is unknown. So for such studies the potential "good mutants" are probably very scarce and we consider that the "cut-bristle" trait, with its easy identification and persistence through ageing and death, could be an available marker.

\section{ACKNOWLEDGMENTS}

The authors thank $\mathrm{C}$ Biémont for his judicious advice in the editing of this text and $\mathrm{A}$ Heizmann for her valuable technical assistance with breeding.

\section{REFERENCES}

Anonymous (1980) Report on consultant's meeting on genetic sexing mechanism for the Mediterranean fruit fly, Ceratitis capitata. Int Atomic Energy Agency, Vienna (mimeograph) 
Carante JP (1983) Proposals for a uniform genetic nomenclature for Ceratitis capitata Wied. In: Fruit Flies of Economic Importance (Cavalloro R, ed) AA Balkema, Rotterdam, 156-162

Carante JP, Lemaître C (1990) Some responses to simulated winter stresses in the adults of the Mediterranean fruit fly (Diptera: Tephritidae). Ann Entomol Soc Am $81,36-42$

Cavicchi S (1973) An orbital bristle mutant in Ceratitis capitata Wied. Genet Agrar 27, 204-209

Lifschitz E (1985) New mutations in the medfly (Ceratitis capitata). In: Report on Research Co-ordination Meeting on the Development of Sexing Mechanisms in Fruit Flies Through Manipulation of Radiation-Induced Conditional Lethals and Other Genetic Measures, 15-19 July 1985, Vienna. Int Atomic Energy Agency/Food Agric Org United Nations, Vienna, 5th working paper

Lifschitz E, Cladera JL (1989) Cytogenetics and sex determination. In: World Crop Pests: Fruit Flies, their Biology, Natural Enemies and Control (Robinson AS, Hooper G, eds) Elsevier Sci Publ BV, Amsterdam, vol 3B, 3-11

Mac Leay WS (1829) Notice of Ceratitis citriperda, an insect very destructive to oranges. Zool $J$ No XVI, 475-482

Radu M, Rössler Y, Koltin Y (1975) The chromosomes of the Mediterranean fruit fly Ceratitis capitata: karyotype and chromosomal organisation. Cytologia 40, 823828

Robinson AS, Van Heemert C (1982) Ceratitis capitata, a suitable case for genetic sexing. Genetica 58, 229-237

Rössler Y (1982a) Genetic recombination in males of the Mediterranean fruit fly, and its relation to automated sexing methods. Ann Entomol Soc Am 75, 28-31

Rössler Y (1982b) Recombination in males of the Mediterranean fruit fly (Diptera: Tephritidae) with and without chromosomal aberrations. Ann Entomol Soc Am 75, 619-622

Rössler Y (1985) Effect of genetic recombination in males of the Mediterranean fruit fly (Diptera: Tephritidae) on the integrity of "genetic sexing" strains produced for sterile insect releases. Ann Entomol Soc Am 78, 265-270

Rössler Y, Koltin Y (1976) The genetics of Mediterranean fruit fly, Ceratitis capitata: three morphological mutations. Ann Entomol Soc Am 69, 604-608

Rössler Y, Rosenthal H (1988) Genetics of the Mediterranean fruit fly (Diptera: Tephritidae): eye colour, eye shape, and wing mutations. Ann Entomol Soc Am 81, 561-563

Rössler Y (1989) Genetic maps and mark. In: World Crop Pests: Fruit Flies, their Biology, Natural Enemies and Control (Robinson AS, Hooper G, eds) Elsevier Sci Publ BV, Amsterdam, vol 3B, 15-18

Saul SH (1985) Diagnosing the heterogametic sex in the Mediterranean fruit fly (Diptera:Tephrithidae): the first sex-linked gene. Ann Entomol Soc Am 78, 198-200 Saul SH (1986) Genetics of the Mediterranean fruit fly (Ceratitis capitata (Wiedmann). Agric Zool Rev 1, 73-108

Saul SH, Rössler Y (1984) Sparkling cye trait and the dc locus in the Mediterranean fruit fly, Ceratitis capitata (Diptera: Tephritidae). Ann Entomol Soc Am 77, 561-563 